\title{
CRIMINOLOGIA Y GÉNERO EN EL SISTEMA ECONÓMICO DEL ECUADOR
}

BRENDA CIELAIKA VANEGAS LEÓN

UNIVERSIDAD INTERNACIONAL SEK

ECUADOR

"No, no basta para que el Derecho y la Justicia florezcan en un país que el juez esté dispuesto siempre a ceñir la toga, y que la policía esté dispuesta a desplegar sus agentes; es preciso aún que cada uno contribuya por su parte a esta grande obra, porque todo hombre tiene el deber de pisotear, cuando llega la ocasión, la cabeza de esta víbora que se llama la arbitrariedad y la ilegalidad”. 


\title{
RESUMEN
}

otivar la incorporación de la perspectiva de género dentro de la investigación
criminológica que se hace en Ecuador es el objetivo de este trabajo que se realiza
a partir de la definición de Antonio García-Pablos de Molina sobre Criminología
y la concreción de Tania Patricia Ibáñez Gómez. Gracias a la concepción de género que aporta el Comité para la Eliminación de la Discriminación Contra la Mujer - CEDAW y el marco jurídico constitucional ecuatoriano se hace una aproximación de análisis de las estadísticas de la población por sexos y de las personas privadas de la libertad.

$\mathrm{Al}$ transitar por argumentos científicos de algunas escuelas criminológicas para abordar el régimen penitenciario, la mujer víctima, género y política criminal, control social y el delito como objeto de la Criminología se demuestra la feminización de la pobreza basada en el salario que percibe y sus horas laborables como resultado de la condición socioeconómica lo que posibilita un perfil criminológico de las mujeres privadas de la libertad con contenido socio biológico.

En el camino de esta investigación y desde un enfoque estadístico se encontró los indicadores de: la casi igualdad cuantitativa de la población por sexos. La desigualdad de horas de trabajo y salarios entre varones y mujeres y la escasa participación de las mujeres en la delincuencia, dando como resultado el poco interés de la Criminología con visión de género en el contexto económico y no veraz que la ceguera de la Criminología a la perspectiva de género deviene de los datos empíricos.

Palabras clave: Criminología, género, sistema económico.

\begin{abstract}
The objetive of this paper to encourage the incorporation of the gender perspective into criminological research made in Ecuador. This research was created from Antonio GarcíaPablos de Molina and Tania Patricia Ibáñez Gómez's documents. In this paper I analyzed the statistics of the prison population with definitions Committee on the Elimination of Discrimination against Women (CEDAW) and Ecuadorian Constitution.

In this article demonstrates women's poverty and socioeconomic conditions are the causes for women become criminal.

This research describes the number of women, inequality in payment and work between men and women, the small number of female offenders by lack of interest in gender Criminology on the Economy.
\end{abstract}

Keywords: Women, Criminology, Gender, Economic System. 


\section{INTRODUCCIÓN}

El grave problema de la criminalidad que enfrenta la gobernabilidad democrática del mundo y en el contexto latinoamericano el Ecuador es un fenómeno que afecta a toda la sociedad pero especialmente a los más vulnerables, pobres y excluidos. El costo económico, político y cultural que involucran los altos niveles de inseguridad de todo orden aplaza los efectos positivos de las políticas de inclusión, entre ellas las de género y protección social.

Ecuador al igual que todos los países de Latinoamérica tiene en su legislación sendos documentos que garantizan, protegen y ordenan la igualdad de género en el contexto de un sistema económico social y solidario, cuyo fin es el ser humano y garantiza la producción y reproducción de las condiciones materiales e inmateriales que posibiliten el buen vivir. Sin embargo, se conoce que en la práctica en todos los países la desigualdad persiste; tanto en el vía de los proyectos de desarrollo social, económico y político como en el acceso a la justicia.

La Constitución Política del Ecuador vigente, desde su Preámbulo con poder vinculante dice: "NOSOTRAS Y NOSOTROS, el pueblo soberano del Ecuador. RECONOCIENDO nuestras raíces milenarias, forjadas por mujeres y hombres de distintos pueblos...", en su artículo 3 señala: "Son deberes primordiales del Estado: 1. Garantizar sin discriminación alguna el efectivo goce de los derechos establecidos en la Constitución y en los instrumentos internacionales...”, en su Art. 11, numeral 2, garantiza:

Todas las personas son iguales y gozaran de los mismos derechos, deberes y oportunidades. Nadie podrá ser discriminado por razones de etnia, lugar de nacimiento, edad, sexo, identidad de género,... diferencia física; ni por cualquier otra distinción, personal o colectiva, temporal o permanente, que tenga por objeto o resultado menoscabar o anular el reconocimiento, goce o ejercicio de los derechos...

Ratifica en su Art. 70.- "El Estado formulará y ejecutará políticas para alcanzar la igualdad entre mujeres y hombres,... e incorporará el enfoque de género en planes y programas, y brindará asistencia técnica para su obligatoria aplicación en el sector público".

El Plan Nacional del Buen Vivir 2009 - 2013, razón única para enrumbar hacia un nuevo horizonte a los y las ecuatorianas, plantea la necesidad de implementar un sistema que nos impulse a descubrir un nuevo modo de vida basado en la inclusión, la sustentabilidad y la democracia.

La Cuarta Conferencia Mundial de la Organización de las Naciones Unidas sobre la Mujer adoptada en 1995 fue la plataforma para integrar las cuestiones de género en la totalidad de los programas sociales y quedó claramente establecida como estrategia global promover la igualdad entre los géneros.

Para transversalizar la perspectiva de género, se debe superar el vacío metodológico que aún persiste entre la doctrina, la estrategia y la ejecución de los programas de desarrollo socioeconómico. 
La Secretaría Nacional de Planificación y Desarrollo promueve la supresión de las desigualdades que producen dominación, opresión o subordinación entre personas y en la creación de escenarios que fomenten una paridad que viabilice la emancipación y la autorrealización de las personas y donde los principios de solidaridad y fraternidad puedan prosperar y con ello la posibilidad de un mutuo reconocimiento (SENPLADES, 2009).

Se entiende que varones y mujeres somos seres complementarios, iguales y corresponsables de los destinos de la humanidad. Por lo que, apoyar la promoción de la igualdad es contribuir a institucionalizar el género en todo trabajo que se realice y más en el académico para coadyuvar en la formulación de políticas, la gestión de programas y la elaboración e implementación de proyectos para que se erradiquen las formas de discriminación hacia la mujer en concordancia con los tratados y convenciones internacionales de cuales el Ecuador es ratificante.

De conformidad con los distintos tratados internacionales, la discriminación es toda distinción, exclusión, restricción, o preferencia basada en atributos de la persona que tenga por objeto o por resultado, anular o menoscabar el reconocimiento, goce o ejercicio, en condiciones de igualdad, de los derechos y libertades.

La Corte Interamericana de Derechos Humanos entiende por discriminación por orientación sexual, identidad de género o expresión de género toda distinción, exclusión, restricción o preferencia de una persona por estos motivos que tenga por objeto o por resultado -ya sea de jure o de facto- anular o menoscabar el reconocimiento, goce o ejercicio, en condiciones de igualdad, de los derechos y libertades, teniendo en cuenta las atribuciones que social y culturalmente se han construido en torno a dichas categorías (OEA/Ser. G OEA. CP/CAJP/INF. 166/12 - 23 /04/ 2012).

En concordancia con el pensamiento de casi todos los criminólogos actuales, (AEBI M. F. 2004). Nos hace ver que: "Las teorías criminológicas que no analizan el fenómeno de la desviación en el contexto de la estructura socioeconómica en que se produce deben ser rechazadas porque no han comprendido la esencia misma del fenómeno estudiado, inserto como eje transversal para el análisis la política económica del país a través de la Constitución en su artículo 283 que define:

El sistema económico es social y solidario; reconoce al ser humano como sujeto y fin; propende a una relación dinámica y equilibrada entre sociedad, Estado y mercado, en armonía con la naturaleza; y tiene por objetivo garantizar la producción y reproducción de las condiciones materiales e inmateriales que posibiliten el buen vivir. 
Desde un enfoque biopsicosocial el desconocimiento sobre las causas de las diferencias cuantitativas y cualitativas entre la criminalidad masculina y femenina no facilitan el estudio sobre las causas de la criminalidad en general y tampoco existen teorías confirmadas o desvirtuadas sobre los fenómenos de la criminalidad femenina. La feminización de la pobreza produce el estado de vulnerabilidad de la mujer, lo que le hace presa fácil para ingresar en la delincuencia. Además no existen respuestas idóneas para superar la victimización de la mujer.

Se utilizan los métodos inductivo, deductivo, estadístico y las combinaciones necesarias de éstos, con los que se tratan los procedimientos lógicos de la investigación como el análisis y la síntesis; efectuando procesos de abstracción científica sobre la base de lo esencial, estos procesos de inferencia con diferente punto de partida, indispensables y complementarios en esta investigación.

El tema en estudio, incluye una gran diversidad de disciplinas; resultando de esto un amplio número de herramientas de consulta especializada en versiones impresas y digitales, la investigación documental y bibliográfica en este trabajo se caracteriza con la definición y utilización de documentos; recolección, selección y análisis para presentar una investigación coherente.

La compilación ordenada de referencias bibliográficas posibilita redescubrir hechos, cuya finalidad es motivar la incorporación de la perspectiva de género dentro de la investigación criminológica que se hace en Ecuador en el contexto socio económico.

Con estos antecedentes se comparte una reflexión personal sobre el tema, Criminología y Género en el Sistema Económico del Ecuador, a través de la interpretación de las cifras oficiales de la población privada de la libertad que ofrecen los principales centros de rehabilitación social, así como de la revisión de algunos de los más reconocidos trabajos relacionados con la Criminología. Se espera que las conclusiones y convicciones desde un punto de vista práctico sean visibilizadas como un pequeño aporte a la comunidad educativa. Y como bien apunta Ramiro Ávila (2009) "El género ayuda, abre los ojos, abre puertas mentales, es necesario, es útil".

\section{LA CRIMINOLOGÍA}

García define la Criminología como:

Una ciencia empírica e interdisciplinaria, que se ocupa del estudio del crimen, de la persona del infractor, la víctima y el control social del comportamiento delictivo, y trata de suministrar una información válida, contrastada, sobre la génesis, dinámica y variables principales del crimen - contemplado éste como problema individual y como problema social- así como sobre los programas de prevención eficaz del mismo, las técnicas de intervención positiva en el hombre delincuente y los diversos modelos o sistemas de respuesta al delito (García-PM 2007). 
Tania Patricia Ibáñez Gómez, concreta: "La Criminología es una ciencia interdisciplinaria que tiene por objeto conocer las conductas antisociales y sus factores contribuyentes con el fin de evitarlos y combatirlos, siendo su fin primordial la prevención” Ibáñez (2010).

\title{
EL GÉNERO
}

El Comité de Naciones Unidas a través de la CEDAW define: "género se refiere a las identidades, las funciones y los atributos construidos socialmente de la mujer y el hombre y al significado social y cultural que se atribuye a esas diferencias biológicas” (OEA/Ser, G. CP/ CAJP/INF. 166/12. 04 2012).

Uno de los temas que más interesa a la Criminología actual es lo referente a la prevención del delito para lograr la paz social y los resultados de investigación que se obtienen a partir de la construcción social llamada género. Sobre el asunto, diversos estudios han demostrado que el control social que se ejerce sobre las mujeres no es el mismo que se ejerce sobre los varones, lo que explica las deficiencias de la actuación del sistema penal y los estereotipos femeninos que se han elaborado para exculpar a los hombres y justificar su superioridad.

La construcción social basada en las diferencias biológicas deviene fatalmente en desigualdades que implica que el modelo de lo humano es el varón. Es parcial, porque excluye a la otra, a quien, por siglos se le ha dado y hoy, en el siglo XXI se le sigue dando un trato desigual, donde los condicionamientos diseñados para el rol femenino emergen como naturales.

Los estudios de género deben contribuir a la Criminología con innovaciones teóricas sobre control social y política criminal para demostrar que los factores económicos, políticos y culturales afectan de manera diferente a hombres y mujeres.

La propuesta con una visión de género sería entonces, reconstruir lo aprendido, visibilizando a la mujer y empoderándola de su condición de persona con derechos y obligaciones con igualdad ante la ley; pero con necesidades y carencias diferentes a las de los varones. Como explica (MCDOWELL 2009)

\begin{abstract}
...”Aunque no abrigo la menor intención de pintar a la mujer como una víctima, no puedo dejar de constatar su sometimiento a formas concretas de dominación y violencia. En tales circunstancias, mientras no desaparezcan las diferencias que las discriminan -..--, las mujeres tendrán que seguir hablando como mujeres y proclamando la idea de un futuro mejor. Como afirma Nancy Fraser: «Las feministas necesitan tanto la deconstrucción como la reconstrucción; desestabilización de la ideología y proyección de una esperanza utópica» (1991).
\end{abstract}

Concordando con la propuesta de Maureen Cain de ver a la criminología Feminista como una ciencia Transgresora, creando espacios “sólo de las mujeres”,... a partir de tres estrategias: 
la reflexividad, la de-construcción y la re-construcción del discurso y de las prácticas.75”.

Hasta la afirmación de los criminólogos en la actualidad, de que "la mujer delinque menos" está cargada de exclusión. Sin embargo, para los sistemas punitivos de la actualidad prácticamente la mujer no existe, todos los resultados son antropocéntricos. La mujer está subsumida en el modelo del varón. Corrobora esta afirmación Badinter (2009) al citar a Annelise Maugue.

Aunque pretende negarlo, el hombre sigue siendo el criterio a partir del cual se mide a la mujer. Él es el uno, legible, transparente, familiar. La mujer es la otra, extranjera e incomprensible. Mejor dicho, sea cual fuere el modelo elegido para hablar de los sexos -semejanza o diferencia -, el hombre siempre se presenta como el ejemplar más logrado de la humanidad, el absoluto a partir del cual se juzga a la mujer.

Dentro de este contexto Zaffaroni (2009) explica: ..., después del Malleus, los sucesivos discursos criminológicos casi no volvieron a mencionar a las mujeres hasta hace poco menos de veinticinco años, salvo referencias tangenciales y esporádicas. La criminología de los últimos cinco siglos sólo se ocupa de los varones, lo que es altamente significativo teniendo en cuenta que los discursos no sólo expresan lo que dicen sino también lo que ocultan y que los operadores del saber no sólo se manifiestan en lo que ven sino también en lo que dejan de ver.

Las estadísticas, elementos claves para visibilizar las desigualdades no son tomadas en cuenta, para las investigaciones criminológicas, como por ejemplo, todo lo que nos dicen las siguientes cifras:

- La población total mundial para el año 2011 fue estimada en 6.852 millones de personas, en números redondos. El Informe de la Organización de Naciones Unidas 2011 afirma que de esa cifra, un total de 3.450 millones corresponde a personas del sexo masculino y 3.402 millones a personas del sexo femenino. Según las estadísticas del Instituto Nacional de Estadísticas y Censo 2010, de 14.483.499 habitantes en el Ecuador, el 50,4\% de habitantes son mujeres y el 49,6\% son varones. Ya no persiste entonces la idea de que "para cada hombre existe más de 2 de mujeres". Hoy en día la población femenina casi es igual en cifras que la masculina. “...el promedio de mujeres presas en el mundo se mantiene por debajo de $4 \%$ con respecto a los varones” afirma Azaola (2004).

En Ecuador Según los últimos datos del Instituto Nacional de Estadísticas y Censos, 2010: del total de la población privada de la libertad el $91,7 \%$ son varones y tan solo el $8,3 \%$ son mujeres. Éstas constituyen una minoría en todos los sistemas penitenciarios del mundo. El hacinamiento que sufren es muy similar al que soportan los varones en los centros de rehabilitación social. 
No obstante, su doble vulnerabilidad considerada en la Constitución, la población penal femenina tiene sus propias necesidades y un perfil delictivo que debe ser estudiado para especificarlo y mediante las políticas criminales orientarlo hacia la prevención. De los pocos estudios realizados sobre la condición de las mujeres privadas de la libertad en Ecuador, (Edwards 2008) (Pontón. FLACSO 2006) coinciden en indicar que el perfil de éstas, según el delito cometido, ha cambiado, tomando mayor relevancia el uso, transporte y venta de drogas; perfil coincidente con la población carcelaria de Latinoamérica (Miralles 1993).

El sistema económico ecuatoriano se integra por las formas de organización económica pública, privada, mixta, popular y solidaria, y las demás que la Constitución determina en el Art 283, tales como, la economía popular y solidaria que incluye sectores de cooperativismo, asociaciones y comunitarios.

Este marco constitucional reconoce y garantiza las prácticas y experiencias solidarias de hacer economía estableciendo las condiciones necesarias para favorecer la edificación de un sistema económico social fundamentado en el crecimiento económico y acorde a la realidad de nuestro pueblo y de sus prácticas ancestrales; concretándose en: el Código Orgánico de la Producción, la Ley Orgánica de la Economía Popular y Solidaria, la Ley Orgánica del Sistema Nacional de Contratación Pública, Código Orgánico de Organización Territorial, Autonomía y Descentralización, entre otras.

El sistema económico debe incluir políticas criminales con perspectiva de género e incorporar los costos de mecanismos de rehabilitación y reinserción social como políticas de control social y de prevención. Además es preciso que la distribución de los recursos, contenga otros indicadores propios y relacionados con la situación de la población penitenciaria, tales como alimentación, salud, educación y productividad.

La evolución del gasto penitenciario en el presupuesto de los centros de rehabilitación social pasó de USD 6,73 millones en 2001 a USD 27,15 millones en 2004. (Núñez, FLACSO 2006). El avance sigue, lo cual posibilita el déficit de la capacidad instalada en los centros que bajó de 116\% en el año 2008 al 64\% en el año 2011. La inversión pública a favor en este sector pasó de 10 millones de dólares en el 2007 a 150 millones en el 2011, quince veces más, lo que ha permitido reducir la sobrepoblación carcelaria de 170\% en el año 2007, a menos del 70\% en el año 2011.

Los centros disponen actualmente de departamentos psicológicos, educativos, laborales y sociales y se ha mejorado sustancialmente el servicio de alimentación. Igualmente, se han creado bibliotecas y talleres para diferentes oficios, con el fin de capacitar y de encaminar hacia actividades productivas (Avances Ecuador 2013). 


\section{LA FEMINIZACIÓN DE LA POBREZA}

Según la ONU: en el mundo, las mujeres ganan como promedio un poco más del 50\% de lo que ganan los varones. Viven en la pobreza y a menudo se ven privadas del acceso a recursos de importancia crítica, como los préstamos, la tierra y la herencia. No se recompensa ni se reconoce su trabajo. Sus necesidades en materia de salud y nutrición no son prioritarias, carecen de acceso adecuado a la educación y a los servicios de apoyo, y su participación en la adopción de decisiones en el hogar y en la comunidad es mínima. Atrapada en el ciclo de la pobreza, la mujer carece de acceso a los recursos y los servicios para cambiar su situación.

También advierte que se han acrecentado las diferencias entre varones y mujeres. Esto supone una mayor "feminización de la pobreza", a lo que se añade la "infantilización" del mismo fenómeno. La feminización de la pobreza se debe al aumento en la región de la discriminación y segregación por sexo, a los menores salarios en los empleos a los que acceden las mujeres y menos oportunidades de conseguir empleos formales y estables, explicó Alicia Bárcena ONU 2012.

Según los datos del INEC y ONU-MUJERES. Mujeres y hombres del Ecuador en Cifras III 2013:

- El salario que percibió la mujer a nivel nacional hasta diciembre del año 2012 fue de un promedio mensual de $\$ 374$ y el del varón $\$ 445$.

- El 42,1\% de varones están asegurados, frente a las mujeres con algún tipo de seguro que hacen un $39,8 \%$.

- Las horas promedio que trabaja en la semana a nivel nacional la mujer son 77:03 y las que labora el varón 61:1; acrecentándose en la provincia de Pichincha a 80:34 horas semanales que labora la mujer.

La feminización de la pobreza produce el estado de vulnerabilidad de la mujer. La Constitución en el Art. 35 se refiere:

Las... personas privadas de libertad..., recibirán atención prioritaria y especializada en los ámbitos público y privado. ... El Estado prestará especial protección a las personas en condición de doble vulnerabilidad.

En concordancia con el Art. 51 y el 203 numeral 4 "En los centros de privación de libertad se tomarán medidas de acción afirmativa para proteger los derechos de las personas pertenecientes a los grupos de atención prioritaria”.

Concreta la Constitución, en su capítulo de la Inclusión y equidad, artículo 340:

El sistema nacional de inclusión y equidad social es el conjunto articulado y coordinado de sistemas, instituciones, políticas, normas, programas y servicios que aseguran el ejercicio, garantía y exigibilidad de los derechos reconocidos en la Constitución y el cumplimiento de los objetivos del régimen de desarrollo... 
Art. 341.- El Estado generará las condiciones para la protección integral de sus habitantes a lo largo de sus vidas, que aseguren los derechos y principios reconocidos en la Constitución, en particular la igualdad en la diversidad y la no discriminación, y priorizará su acción hacia aquellos grupos que requieran consideración especial...

Como corolario a las normas precedentes, Jaramillo (2009), señala: “... se ha mostrado que incluso cuando el derecho protege los intereses y necesidades de las mujeres e introduce su punto de vista, en su aplicación por instituciones e individuos moldeados por la ideología patriarcal, ha desfavorecido a las mujeres".

\section{PERFIL CRIMINOLÓGICO DE LAS MUJERES PRIVADAS DE LA LIBERTAD}

Por la experiencia de capacitar en los centros de rehabilitación social, tanto de varones como de mujeres a través del Centro de Mediación del Municipio del Distrito Metropolitano de Quito, se describe el perfil de las mujeres privadas de la libertad atendiendo a la actividad delictiva objeto de su internamiento, según los resultados de diversas encuestas y entrevistas realizadas a las personas privadas de la libertad, a funcionarios del Consejo Nacional de Control de Sustancias Estupefacientes y Psicotrópicas y empleados de la Dirección Nacional de Rehabilitación Social en los años 2009, 2010 y 2011.

1. Delito contra las personas como asesinatos, homicidios, infanticidios y parricidios.

2. Trata de personas.- Entendidos como el promover, inducir, participar, facilitar o favorecer la captación, traslado, acogida, recepción o entrega de personas recurriendo a la amenaza, violencia, engaño o cualquier otra forma fraudulenta, con fines de explotación ilícita, con o sin lucro.

3. Contra la propiedad: hurtos, asaltos, robos con intimidación, extorción, estafa y otras defraudaciones; cometidos principalmente por mujeres jóvenes y drogodependientes.

4. Contra la fe pública: falsos testimonios, falsificación de firmas, cheques y otros documentos en general.

5. Contra la salud pública, los contemplados en la Ley 108 - Ley de Sustancias Estupefacientes y Psicotrópicas de Ecuador, "En 2009, el 80 por ciento de todas las mujeres detenidas en El Inca, la prisión más grande para mujeres del país, se encontraban detenidas por delitos de drogas" Edwards (2008), pueden agruparse así: 5.1 Redes de grandes traficantes.- Extranjeras que hacen de correos de las mafias, huyendo de situaciones y problemas económicos en su país: Colombia, Perú, Chile, Venezuela, EE.UU. y europeas, conforman el 23\% de población carcelaria de mujeres en la cárcel del Inca, según datos aportados por Edwards (2008). 
2 Redes de pequeña distribución, generalmente drogodependientes, se incluyen en estas redes para autoabastecerse. A menudo se conjugan con delitos contra la propiedad y el ejercicio de la prostitución al más bajo nivel (parques, carreteras, autos). 5.3 Redes de subsistencia económica familiar. Una mayoría de mujeres adultas, no drogodependientes, tampoco consumidoras eventuales, para las que la venta de droga se ha convertido en el medio más frecuente de subsistencia y economía familiar; muchas de ellas reincidentes.

5.4 Redes de mulas. Según la Defensoría Pública, Ernesto Pazmiño, señala:

Muchas 'mulas' o micro-comerciantes son madres que se involucran en la actividad de transportar drogas a cambio de 200 ó 300 dólares: "Nosotros hemos demostrado [hicimos un trabajo con la prensa] de que las mulas, principalmente las mujeres que están presas, tienen afuera a hijas menores de edad que, cuando sale la persona [mamá], retornaron a su hogar (...)... y encontraron a sus hijas de 12 años, 16 años, prostituidas; no tenían otra cosa qué hacer. $\mathrm{O}$ a los hijos ya entrados en la delincuencia”. Una vez encarceladas y sentenciadas, son cada vez más escasas las oportunidades para que estas mujeres trasformen sus vidas y se alejen de los bajos círculos del comercio de la droga.

Las mujeres son más vulnerables a convertirse en 'mulas' y/o micro-comerciantes de drogas no sólo debido a las altas tasas de desempleo y la responsabilidad económica de sus hijos, sino también por ser presa fácil de sus esposos, amantes o explotadores quienes las fuerzan, física o verbalmente, a hacerles este 'único favor' (Edwards 2008).

\section{PERFIL SOCIAL DE LA MUJER PRIVADA DE LA LIBERTAD}

El perfil más reiterado que comparten las mujeres privadas de la libertad en nuestros centros de rehabilitación social concretamente es: pertenecer a familias disfuncionales y extensas; de vivencia familiar conflictiva, con separaciones, violencia intrafamiliar, promiscuidad sexual, abusos sexuales entre la familia. Familiares próximos con antecedentes penales. Abandono temprano o fracaso escolar. Nulo aprendizaje o experiencia laboral. Maternidad precoz. Frecuentes separaciones y fracasos matrimoniales Alta incidencia y temprana de consumo de drogas, alcohol y ejercicio de la prostitución, entre otras.

Perfil coincidente con los de las mujeres que habitan los barrios marginales de los cinturones de las ciudades de Quito y Guayaquil o el de la aplicación del III Paso de Focalización dado por ONU Habitat (2010).

La venta de estupefacientes en pequeña escala es para la mujer que generalmente se encuentra como responsable de la subsistencia familiar una entrada económica para hacer frente a los gastos básicos de supervivencia. Además, en un alto porcentaje de estas, tienen 
a su vez, a su marido o compañero sentimental en la misma circunstancia, lo que implica su papel circunstancial y secundario de dependencia y complicidad en la actividad delictiva.

Luego del indulto a las llamadas 'mulas' del narcotráfico a solicitud del presidente Rafael Correa en julio de 2008 se advierte una leve y paulatina disminución tanto del número real como del porcentaje de mujeres privadas de la libertad por delitos relacionados con drogas, señalan Edwards y Youngers (2010).

En la cárcel de mujeres El Inca de Quito, donde casi el 80 por ciento de las internas estaban condenadas por delitos relacionados a drogas, la combinación del indulto con la regla del dos por uno llevó a un considerable mejoramiento de las condiciones carcelarias. Durante las reformas temporales, se otorgó la libertad a tantas mujeres que cada prisionera pudo dormir en una cama, mientras que antes solían compartir una cama entre tres personas. Además, el nivel de violencia disminuyó considerablemente, y el acceso a los servicios existentes mejoró tremendamente.

\section{PERFIL CRIMINOLÓGICO CON EXPLICACIONES DE CONTENIDO BIOLÓGICO}

Lombroso y Ferrero. (1895), de sus estudios podría entenderse que:

“... el estadio inferior en que se encuentra la mujer podría ser consecuencia de la mayor inactividad que caracteriza a la mujer respecto al varón, al igual que la inmovilidad del óvulo respecto al zooesperma... de ahí que la mujer delincuente, por el hecho de estar menos evolucionada: presentaría una inferior tasa de delitos por su menor capacidad para delinquir - su mayor crueldad se debería a su mayor identificación con lo primitivo, de ahí su predominio en la comisión de delitos de sangre -. Su mejor capacidad de adaptación llevaría a combinar las peores características de la mujer: astucia, rencor y falsedad; con aquellas otras de la criminalidad masculina, disponiendo además de una mayor habilidad en su trato con la justicia. Concluyendo: su criminalidad resulta un comportamiento masculinizado e impropio de su verdadera naturaleza... una doble anormalidad: biológica y social,... y por ser una doble excepción, la mujer criminal es un monstruo". Teorías condenadas en la actualidad por ser discriminadoras, además de perversas.

Concordando con lo aseverado por Sánchez (2004): estudios e investigaciones sobre el problema de la prostitución, por ejemplo, llevan a la conclusión de que la prostituta no es, como se piensa habitualmente, el símbolo de la desviación femenina como decía Lombroso, sino un símbolo de la victimización que consagra la estructura patriarcal. 


\section{EL RÉGIMEN PENITENCIARIO}

Los factores de orden normativo inciden en el comportamiento de la delincuencia femenina, el régimen penitenciario elaborado para varones se traslada automáticamente a las mujeres, sin tener en cuenta su diferente idiosincrasia, imponiendo normativas internas y de organización directamente redactadas para los reclusos.

Cuando se ha visitado el centro de rehabilitación femenino del Inca en el norte de Quito, es imposible no recordar sus pabellones con los nombres de los barrios de la ciudad: El Bosque, El Condado, Miraflores, y otros como El Batán, Dorado, Floresta, Quito Tenis, Amazonas y Altamira. No deja de sorprender la limpieza y el orden que impera en unos y el descolorido desorden de otros. Reñido el discurso que dan las y los guías, para ellos "las mujeres están ubicadas en los pabellones de acuerdo al delito y al tiempo de condena". Según las internas "Están ubicadas en los pabellones de acuerdo al dinero que pueden dar en el sistema carcelario para sobrevivir".

El recorrido por los escenarios de estas mujeres, los talleres, la cocina y la capilla nos acercan al ámbito femenino. ¿En realidad su estadía y actividad las prepara para los escenarios fuera de la cárcel?:

Sobre este particular Yagüe Olmos (2011) nos alerta:

Un enfoque diferencial, por ejemplo en labores de prevención o formativas. La mujer que llega a prisión se encuentra sometida a unos parámetros de marginación y deterioro marcadamente superiores al de la media de los hombres, y en opinión de los expertos, es su pronóstico de inserción mucho más difícil debido a los condicionantes sociales y psicológicos de procedencia.

\section{LA MUJER VÍCTIMA COMO OBJETO DE LA CRIMINOLOGÍA}

A la Victimología le interesa el estudio de la víctima no sólo de los delitos en sentido estricto, sino de las conductas desviadas que provocan perjuicios a terceros aún a pesar de que estas conductas puedan estar socialmente admitidas. Le concierne, además la víctima de comportamientos y situaciones injustas aunque no tipificadas y ello, en la medida en que no siempre lo injusto es ilegal.

Tanto la Criminología como el Derecho penal se centraban en el delincuente, olvidándose de la víctima, quien precisa, de un proceso de resocialización o reinserción y en cualquier caso se encuentra habitualmente desprotegida, la Criminología actual, estudia la pareja delincuentevíctima, entendiéndose a ambos sujetos como íntimamente unidos en la explicación del delito.

\section{LA MUJER COMO UNA VÍCTIMA DE RIESGO CON CARÁCTER DE ESTABLE}

En Ecuador, 6 de cada 10 mujeres han vivido algún tipo de violencia, 1 de cada 4 mujeres 
ha vivido violencia sexual; sin embargo, la violencia psicológica es la forma más recurrente de violencia de género con el 53,9\%. Del total de mujeres que han vivido violencia física, el 87,3\% lo ha hecho en sus relaciones de pareja (INEC 2012).

De acuerdo a datos del Ministerio de Salud 2011, en el Programa de Violencia de la Dirección Provincial de Salud del Azuay, el 85\% de las víctimas fueron mujeres.

Las condiciones de vulnerabilidad social de la mujer en el mundo son desconcertantes y en el Ecuador es una realidad que lacera el alma, pues resulta que la mayoría de víctimas son mujeres. Las respuestas idóneas para superar la victimización de la mujer no se tiene aún.

Debemos reconocer que la igualdad formal ya existe declarada en sendos instrumentos internacionales, la Constitución y otras leyes. En la práctica las respuestas de ejercicio de derechos están plagadas de inequidades y hace que la mujer se encuentre como una víctima de riesgo con carácter de estable según los estudiosos de la sociología y la criminología. En este contexto, las mujeres pobres, las campesinas y las pertenecientes a minorías étnicas se encuentran en una situación aún más preocupante, sin acceso a la justicia y víctimas de discriminaciones en todas sus formas. Sin embargo de que se trata de una problemática evidente, la invisibilidad campea y no existe reflexión acerca de las necesidades específicas de atención del colectivo de mujeres, que día a día son víctimas de toda clase de violencias, detectadas en documentos de diagnóstico efectuados en Ecuador especialmente por el Consejo Nacional de Mujeres CONAMU. Si bien, la Constitución reconoce la doble vulnerabilidad de las mujeres privadas de la libertad, en la práctica es un crimen que se repite continuamente y las autoridades no pueden aún controlar; la Comisión Ecuménica de Derechos Humanos en el informe 078 - CEDHU/11 en la Audiencia sobre la situación penitenciaria del Ecuador afirma: "en los centros de detención de mujeres el acoso sexual hacia ellas o sus visitas es una forma frecuente de maltrato".

Se entiende, que el crimen hoy en día, debe comprenderse como conflicto o enfrentamiento personal, interpersonal y social, repetido a través de la historia, concreto y diferente en su individualidad y tan dolorosamente humano y cotidiano. De allí, la Criminología ve en la y el delincuente una persona normal, de su tiempo. Un ser que lleva en su sangre la herencia genética, que se interrelaciona con sus congéneres y que se acomoda o adapta al medio. Como lo precisa García-Pablos de Molina, aunque sesgado en el varón:

Un ser, en definitiva, inacabado, receptivo, que mira al futuro y puede trascender sus propios condicionamientos. Porque el hombre no es solo Biología: es, también, Historia, Cultura, Experiencia. Factores espaciales, ambientales, interpersonales, culturales, etc. etc., convergen en el escenario criminal, contribuyendo decisivamente al muy selectivo diseño del «perfil» del suceso delictivo (García-PM 2007). 


\section{GÉNERO Y POLÍTICA CRIMINAL}

Binder enseña que se debe tener claro qué la política criminal: "Es el conjunto de los métodos por medio de los cuáles el cuerpo social organiza las respuestas al fenómeno criminal”. En un Estado democrático se encuentra fundado en el respeto a la dignidad humana y a las garantías individuales. Este contexto, nos lleva a la reflexión sobre el tratamiento que se debe dar a cada persona, ya sea: varón o mujer y de acuerdo a sus edades, considerando además factores de orden social, cultural y económico que provocaron determinada conducta (Binder 2010).

Si del 100\% de la población mundial de personas privadas de la libertad el 96\% corresponde a varones y el 4\% a mujeres según la ONU, (Informe 2011). Como se vio en el Ecuador el 91,7\% corresponde a varones y tan solo el 8,3\% a mujeres, de acuerdo a las estadísticas del INEC (2010).

La mujer criminalizada, es repetidamente "virilizada", poseída por un demonio o portadora de una patología degenerativa, dado que la mujer "más o menos normal" contraviene a su propia "naturaleza" cuando comete delitos violentos, razones por las que concurre la creencia social que persiste y afirma que: "existen menos mujeres privadas de la libertad, y que esto se debe a una especie de inmunidad establecida por su naturaleza". Creencia basada en las teorías tradicionales de cortes estigmatizadoras, discriminatorias y perversas.

Esta concepción de la natural inferioridad de la mujer presente en esa especie de "inmunidad establecida por su naturaleza" ha sentado bases para la exclusión penal de la mujer como responsable de conductas típicas, antijurídicas y culpables; posibilitando el control social de la mujer privada de la libertad, a quien se le ha asignado socialmente esa "inmunidad establecida por su naturaleza" esa especie de "posesión demoníaca”. Reiterándose con esto, la discriminación que por género y número se está realizando; dificultando y deteniendo una mínima clasificación o separación en atención a sus características personales, penales o penitenciarias así como el abordaje de la maternidad y acceso al trabajo penitenciario. Todo esto debido al fuerte control ejercido por las estructuras sociales y familiares con respecto a "esa especial naturaleza de la mujer". De este tipo de concepciones y visiones se desprende un doble oprobio de indignidad para la mujer: la condena legal por el delito y la condena social por la anormalidad biológica o sexual. Doble connotación de vínculo maligno que todavía hoy en el siglo XXI subyace en muchas evaluaciones sobre el delito de la mujer. Estas evaluaciones sirven de base para las políticas criminales de represión del crimen. Así, "El derecho penal las excluye como sujetos activos, pero agrava la individualización de la pena que sobre ellas recae, que se basa en un conjunto de falsedades ordinarias en forma de prejuicios de género que pretenden legitimar su rol subordinado” (UNAM 2007).

Ante lo descrito, Ramiro Ávila (2009) nos insta: “Conviene identificar esas normas y cuestionarlas. Un Ecuador más justo y equilibrado lo demanda”.

Desde la tesis que constituye el movimiento de liberación femenina, Rita Simon (1975) en su obra Women and Crime analiza la situación de las mujeres en la 
desviación. Sugiere que a medida que las mujeres irrumpan con mayor importancia en el ámbito laboral, se abrirán nuevas oportunidades para ellas, lo que traería, por ejemplo, una mayor participación en la delincuencia. Al parecer, si cambian las circunstancias del género femenino en la estructura socio laboral, aumentarían también sus incursiones en nuevas formas de desviación. Tal situación elevaría las tasas delictivas y variaría el tipo de delito cometido por ellas, equiparándose con mucha seguridad a la delincuencia asociada con los hombres. En esta misma línea de pensamiento, uno de los primeros aportes que se replanteó la condición de la mujer dentro de la teoría y la investigación de la delincuencia fue el de Freda Adler en Sisters in Crime, esta autora establece una relación entre la emancipación o liberación de la mujer, y los cambios en sus niveles y tipos de conducta delictiva. Conjetura esta criminóloga que al hacerse más autónomas las mujeres, e ir ganando espacios tradicionalmente reservados al otro género, se deberá originar una mayor participación de ellas en el delito, y especialmente en aquellas contravenciones donde el hombre ha tenido mayor prevalencia.

Teorías que para Ecuador se descartarían, puesto que las estadísticas del INEC y ONUMUJERES nos indican que la actividad laboral de la mujer es de un promedio 77:03 horas laborables, frente al promedio de 61:1 que labora el varón ecuatoriano y del total de la población privada de la libertad el $91,7 \%$ son varones y tan solo el $8,3 \%$ son mujeres. Es decir que, aunque la mujer ha ganado espacios laborales del hombre, sigue delinquiendo menos.

Las investigaciones sobre las diferencias entre varones y mujeres es una práctica relativamente nueva en Criminología y es un nuevo horizonte donde anclar para aclarar muchos de los vacíos existentes en las explicaciones del delito, del delincuente, el control social, la política criminal y la prevención.

En palabras de Garrido:

“...en Criminología el género no puede seguir siendo considerado una variable más (del mismo nivel que la educación, la familia, la inteligencia, etc.) a la hora de estudiar la delincuencia (...) el género constituye un factor estructural, que divide la vida social en dos maneras distintas de afrontarla e interpretarla: la de las mujeres y la de los hombres" (Garrido y otros, 2006).

Cabe señalar, igualmente, que la inclusión de la mujer desviada como aspecto crucial de la Criminología se inicia con el feminismo en los años setenta. Esta Criminología contiene un testimonio muy promisorio: existe algo en el género como característica propia para que las mujeres delincan en menos proporción que el hombre, puede ser el eslabón perdido de las mujeres, el que ayude a encontrar las causas del delito. Sin embargo esta teoría no ha tenido continuidad. 


\section{CONTROL SOCIAL}

García Pablos De Molina señala que el concepto de control social es un concepto sociológico neutro, descriptivo que hace referencia a "ciertos procesos sociales que recaban la conformidad del individuo, sometiéndole a las pautas, modelos y requerimientos del grupo; cohesión, disciplina, integración, son, pues, términos que describen el objetivo final que persigue el grupo, la sociedad, para asegurar su continuidad frente al comportamiento individual irregular o desviado".

Entre los años 70 - 75 aparece la tesis de la Liberación de la Mujer, con esta la concepción de discriminación de género. Pensamiento que siendo una construcción social que discrimina a la mujer por su diferencia biológica del sexo realiza el control social, entendido como las respuestas negativas suscitadas por determinados comportamientos que vulneran las normas sociales; es decir que, no cumplen las expectativas de conductas asociadas a un determinado rol social.

La sociedad ha elaborado el perfil para la mujer normal y para la mujer desviada a través de estereotipos; así la mujer normal es aquella que se adapta al modelo de conducta que responde a lo que se espera de ella (mujer buena, honesta, hogareña, femenina, cuidadosa, sumisa). En tanto que el perfil de la mujer desviada es sexualmente degradante, masculinizada, callejera, drogadicta y prostituta.

\section{EL DELITO COMO OBJETO DE LA CRIMINOLOGÍA}

La Criminología observa al delito desde una perspectiva empírica, si bien, el Derecho Penal establece que el delito, no deja de ser un hecho físico y social al mismo tiempo, deduciéndose que este pertenece al mundo del deber ser en su entidad normativa, también pertenece al mundo del ser y se debe investigarlo en su realidad natural, es decir, como causa de las causas.

Seguir repitiendo que el delito es "acción típica, antijurídica y culpable " y en algunos casos "punible" es seguir a la zaga del pensamiento, de ese pensamiento que define al "ciudadano del mundo" del "ser planetario" que habita el universo regido por el fenómeno de la globalización y que está tratando de construir la sociedad del conocimiento; en especial para el jurista es no ocuparse de los problemas sociales, los cuales son parte de las obligaciones y ejercicio del Derecho.

Como aclara Alicia E. C. Ruiz (2009), el derecho configura la subjetividad y las identidades y por esa vía consagra o denuncia formas de discriminación, interviene en los espacios de conflicto que se generan a partir de esas configuraciones y en las inevitables secuelas individuales y sociales que provocan. Reconocer a alguien como "sujeto de derecho", resignifica el discurso acerca de ese alguien. La operatividad de ese reconocimiento implica una intervención en el mundo simbólico, con consecuencias tremendamente reales. 
Consciente que nadie puede ofrecer una respuesta completa, segura y aceptable por todos, concluyo mi reflexión afirmando que la Criminología debe transversalizar el género en el contexto económico como una combinación armónica de originalidades incesantemente multiplicadas e iniciadas en el punto exacto donde cada persona se diferencia de las demás.

\section{CONCLUSIONES}

Los estudios criminológicos incluyen una amplia visión de argumentos para efectuar reformas legales, desde la pretensión de que el sexo resulte neutral como criterio legal hasta el tratamiento individualizado a todo ser humano sin discriminación alguna, ante esto, el Derecho debe posibilitar la visibilización de la subordinación de las mujeres y construir normas que transformen la desigualdad. Es necesario entonces, deconstruir la Criminología y el modelo androcéntrico que conocemos para reconstruirla, develando el simbolismo del género que se encuentra oculto en la lucha por la liberación femenina.

Cada uno de los argumentos analizados identifica un aspecto diferente del Derecho y denuncian su fracaso por ostentar el poder masculino. Lo que espero es que, mejorando las teorías sobre las que aplicamos nuestra práctica cotidiana, logremos vislumbrar mejor; lo que es igualdad ante la ley y las diferencias entre los seres humanos.

La criminología tradicional declara la delincuencia femenina a partir de sus características asociadas a su sexualidad. La especie de "inmunidad establecida por su naturaleza" y exhibe perversamente tanto su comportamiento normal como su conducta desviada.

Una tarea clave de la Criminología sigue siendo explicar a través de la construcción social del género la razón o razones del ¿por qué las mujeres delinquen menos que los hombres? A través de la visión de género en las investigaciones de Criminología se intenta conciliar algunos elementos que diferencian a la mujer del hombre para explicar los bajos niveles de criminalidad femenina contrastando la participación delictiva de ambos género. Es decir que, aunque la mujer ha ganado espacios laborales del varón, sigue delinquiendo menos. Por ello, la necesidad de readecuar valorativa, estratégica e institucionalmente las políticas criminales en materia de este difuso y complejo fenómeno que resulta la criminalidad femenina.

Imperiosa es la necesidad de comenzar a cultivar la perspectiva de género en la Criminología que se hace en nuestro país, fundamentado sus investigaciones y argumentaciones sobre la delincuencia en los estudios estadísticos, sociales y económicos, entendiendo que el peso del género en la conducta desviada no reside únicamente en las estadísticas; lo que significaría tratar al género como un sistema metodológico que organice y diferencie, en categorías masculino y femenino, las observaciones empíricas y las deducciones derivadas de estas.

$\mathrm{Al}$ incluir la perspectiva de género en la Criminología se abre una verdadera posibilidad de reconocer las variables de riesgo y protección que son importantes para la delincuencia de mujeres y varones, con esta inclusión se podrá apreciar que las circunstancias que influyen 
en la delincuencia de cada género pueden ser diferentes, en algunos casos coincidentes y en otros inesperadas, es decir se debe visibilizar todo lo concerniente al género, para garantizar manifestaciones y deducciones diferenciales en base a las circunstancias propias de ambos sexos; esto direccionará un nuevo horizonte para las teorías criminológicas; falta andar este camino para poder llegar a explicaciones que den cuenta de la conducta criminal femenina, desde una perspectiva de género.

La desigualdad económica feminiza la pobreza y la utilización de la mujer como "mula" del narco tráfico hace la explicación del acrecentamiento de la delincuencia femenina en las cárceles del país. Debería reformarse la Ley 109 para despenalizar la venta de drogas en pequeña escala, en concordancia con el principio constitucional de proporcionalidad.

La escasa peligrosidad social y real de las mujeres, su exigua sofisticación delictiva, los efectos desocializadores, la ruptura y problemática familiar que provoca la privación de la libertad de la mujer, deben ser causas suficientes que posibiliten medidas alternativas a su internamiento, de tal forma que se nivelen equitativamente el daño social cometido, y el castigo atribuible.

Desde la visión de género se lucha por una mayor sensibilización judicial y penitenciaria en el marco de las políticas criminológicas. El trato normativo para varones y mujeres es igualitario, (excepto por la maternidad), sin embargo, de que es obvia la diferencia de su comportamiento y necesidades. No es justo ni saludable que la mujer privada de la libertad siga asimilada a la población masculina, es necesario potenciar una Política penitenciaria específicamente femenina basada en la especialización del personal, incremento y fortalecimiento de los programas formativos, laborales y psicológicos para a través de compatibilizar las normativas estrictamente reglamentarias con una organización centrada en valores de convivencia, responsabilidad y trabajo lograr una verdadera rehabilitación social y reinserción laboral.

\section{REFERENCIAS BIBLIOGRAFICAS}

ADLER, Freda. Sisters in Crime (teoría de la liberación de la criminalidad femenina) EE.UU, 1975 .

AEBI M. F. Crítica de la Criminología crítica. Ediciones Universidad de Salamanca, 2004.

AVANCES ECUADOR. Presidencia de la República del Ecuador de Mayo 20 de 2012. Disponible en: www.slideshare.net/PresidenciaEc/avances-ecuador enero 6 de 2013.

ÁVILA, Santamaría Ramiro. Judith Salgado y Lola Valladares. El género en el derecho. Ensayos críticos, Compilador, compiladoras. Serie Justicia y Derechos Humanos N. 12, V\&M Gráficas, 2009. 
AZAOLA, Elena. Género y Justicia Penal en México 2004, disponible en: www.dplf.org/uploads/1190750270.pdf Consulta 20/01/2013.

BADINTER Elisabeth. El Enigma Masculino. La Gran X. Reproducción Serie Justicia y Derechos Humanos N. 12, V\&M Gráficas, 2009. Pág. 90.

BÁRCENA, Alicia. Informe anual de la comisión económica regional de la ONU - 2012.

BINDER Alberto M. La política criminal en el marco de las políticas públicas, bases para el análisis político-criminal. REJ - $\mathrm{N}^{\mathrm{O}} 12-2010$.

CAIN, Maureen. Towards Transgression: New Directions in Feminist Criminology. 1990

Constitución Política del Ecuador 2008.

EDWARDS G. Sandra. La legislación de drogas de Ecuador y su impacto sobre la población penal en el país 2008. Disponible en: http://ctinobar.webs.ull.es/4actividades/LEGISLACION.pdf Consulta 23/01/2013.

Informe sobre Ecuador, Reforma sobre Legislación de Drogas en Ecuador: Generando Impulso para un Enfoque Más Efectivo, Balanceado y Realista.

GARCIA, Pablos de Molina, Tratado de Criminología, Ed. Tirant lo Blanch, Valencia, 1999.

INEC. Estadísticas sociales: Disponible http://www.inec.gob.ec/estadisticas/ Consultado 20/03/2013.

INEC y ONU-MUJERES. Mujeres y hombres del Ecuador en Cifras III 2013. ISBN: 9789942-07-390-7.

JARAMILLO Isabel Cristina. El feminismo y el derecho. Reproducción Serie Justicia y Derechos Humanos N. 12, V\&M Gráficas, 2009. Pág. 122.

LOMBROSO y Ferrero. La Mujer Delincuente, Universidad Zula, 2000.

MCDOWELL Linda. La Definición de género. Reproducción Serie Justicia y Derechos Humanos N. 12, V\&M Gráficas, 2009. Pág. 9.

MIRALLES, Teresa. La mujer: el control formal, Barcelona 1983. 
CEDHU. Audiencia sobre la situación penitenciaria en Ecuador 2011. Informe 078 - 2012.

NÚÑEZ, Vega Jorge. Ciudad Segura 1 - enero 2006. FLACSO Ecuador • PE.4, Quito 2006.

OEA, Derechos Humanos, Orientación Sexual e Identidad de Género. "CIDH” AG/RES. 2653 (XLI-O/11): OEA/Ser. G OEA CP/CAJP/INF. 166/12 23 abril 2012.

RODRÍGUEZ, Juan Antonio. Criminología y género. Venezuela 2009.

RUIZ Alicia E. C. Cuestiones Acerca de Mujeres y Derecho. Reproducción Serie Justicia y Derechos Humanos N. 12, V\&M Gráficas, 2009. Pág. 210.

SÁNCHEZ, Mariana Noemí. La mujer en la teoría criminológica. La Ventana N. 20 - 2004.

SIMON Rita. Women and Crime 1975, traducción RG UMET, Quito 2004.

UNAM- Villeda Miranda Ángela e Iris Rocío Santillán Ramírez - Criminología crítica y perspectiva de género, México 2007.

YAGÜE, Olmos Concepción. Mujer: delito y prisión, un enfoque diferencial sobre la Delincuencia Femenina, Sevilla 2011.

ZAFFARONI, Eugenio Raúl. El Discurso Feminista y el Poder Punitivo. Reproducción Serie Justicia y Derechos Humanos N. 12, V\&M Gráficas, 2009. Pág. 329.

\section{CURRICULUM VITAE Brenda Cielaika Vanegas León}

Doctora en Jurisprudencia, (Universidad Católica de Cuenca, Ecuador). Magister en Gerencia Educativa y Docencia Universitaria (Universidad Metropolitana, Ecuador). Especialista en Derecho Procesal Penal (UMET, Ecuador). Especialista en Mediación (Universidad Internacional SEK, Ecuador). Especialista en Entornos Virtuales (OEA - Virtual Educa). Diplomado Internacional, El Defensor de los Derechos Humanos (UNESCO - Universidad Bolivariana de Venezuela). Profesora Regular de la UISEK, de Derecho Procesal Penal, Criminología, Técnicas de Negociación, Teoría del Delito y de la Pena; y, Delitos en Particular. Profesora invitada de algunas universidades del país.

brenda.vanegas@uisek.edu.ec brendavl@hotmail.com 